\title{
Are rates of school suspension higher in socially disadvantaged neighbourhoods? An Australian study
}

\author{
Sheryl A. Hemphill, John W. Toumbourou, Rachel Smith, Garth E. Kendall, Bosco Rowland, Kate Freiberg and Joanne W. Williams
}

The management of challenging student behaviours including violence, antisocial behaviour and bullying in the school setting are issues that most schools find difficult. Students who engage in antisocial behaviour are often excluded from school through the use of suspension, a temporary prohibition from attending school. Studies in the US have shown that schoolss suspension rates vary greatly. ${ }^{1,2}$ In Australia, recent student-reported rates of school suspension are $10.9 \%$ for boys and $6 \%$ for girls in Years 7 and 9. ${ }^{3}$ Research in the US shows that suspension is used not only for serious behavioural transgressions that threaten the safety of the students themselves or others; it is also used for non-threatening behaviours such as repeated disruption in the classroom, talking back to the teacher and wagging school. ${ }^{2}$ Further, $\mathrm{Wu}$ and colleagues found that although student behaviour predicts school suspension, there are a number of other factors, over which students have no control, that are more important influences. ${ }^{4}$ These include the overall school suspension rate, teacher attitudes that include thinking students are not able to solve their own problems, administrative centralisation for discipline (rather than distribution of authority across personnel) and schools that do not run fairly, firmly and consistently.

Evidence from prospective studies shows that school suspension can have serious unintended negative consequences for the suspended student. These unintended consequences include intensifying academic difficulties, school drop-out, disengagement from school, student alienation, crime and delinquency and alcohol and drug use. ${ }^{1,5-7}$ In two recent papers, it has been shown that school suspension increases the likelihood of the student engaging in antisocial behaviour and violent behaviour 12 months later, even after controlling for a comprehensive range of established risk and protective factors. ${ }^{3,8}$

The detrimental impact of school suspension extends beyond the suspended student. Suspension is associated with reports

Abstract

Issue addressed: Health promotion with adolescents spans many contexts including schools. Income and its distribution, education and social exclusion are key social determinants of health. Exclusionary school policies such as school suspension contribute to exclusion, increase the likelihood of school dropout (reducing educational and subsequent employment opportunities), and negatively impact on student wellbeing. Often excluded students are from socio-economically disadvantaged areas. This paper examines associations between area level socio-economic status (SES) and school suspension in Australian students.

Methods: Students $(8,028)$ in years $6(n=4393)$ and $8(n=3635)$ completed a comprehensive social development survey administered in schools in 30 socio-economically stratified communities in 2006.

Results: Associations between area level SES and school suspension were found. Relative to students in the lowest SES quartile communities, students in mid level and high SES had lower suspension rates. These effects remained after controlling for antisocial behaviour, gender, age and the established risk factors of poor family management, interaction with antisocial peers and academic failure.

Conclusions: Students living in low SES areas are exposed to higher rates of school suspension, at similar levels of adjustment problems. Assisting schools, particularly those with disadvantaged students, to foster school engagement is essential for schools committed to health promotion.

Key words: school suspension, socio-economic disadvantage, school exclusion.

Health Promotion Journal of Australia 2010; 21:12-18

\section{So What}

School suspension is relevant to several social determinants of health. Modifying how school suspension is implemented and developing effective alternatives are crucial. Exclusionary approaches maintain disadvantaged students in situations that reduce their future life opportunities and run counter to health promotion goals. 
from both students and teachers of feeling less safe at school and an uninviting school climate. ${ }^{9}$ At the school level, negative associations between suspension and academic achievement have been reported. ${ }^{9}$

Of further concern are findings that students who receive school suspension often belong to an ethnic minority group or are of low socio-economic status (SES). ${ }^{2,9,10}$ Data from the Safe School Study in the US showed that students whose fathers did not have a full-time job were more likely to have been suspended than students whose fathers did have a full-time job. ${ }^{4}$ Further, students who receive free lunches at school (a proxy for low SES) are more likely than those who do not to have experienced suspension. ${ }^{4}$ Other studies have confirmed the link between schools with higher proportions of students receiving a free lunch and greater rates of suspension. ${ }^{11,12}$ A qualitative study of perceptions of school policies in adolescents from high- and low-income residential areas found that both groups reported that students from high-income areas were more likely to receive mild and moderate behavioural consequences (e.g. moving desks, teacher lecture), and students from low-income areas received severe consequences that were sometimes delivered in a less professional way (e.g. yelled at in front of class, made to stand in corridor all day). ${ }^{13}$

This paper examines the relationship between relative area level SES and school suspension in an Australian sample after controlling for student gender, age and antisocial behaviour. Whether the link between area level SES and suspension remains after adjustment for established student-reported risk factors including poor family management, academic performance and interaction with antisocial peers is also examined. These risk factors were chosen due to their potential associations with both area level SES and school suspension.

\section{Methods}

\section{Sample and Procedure}

Data used in this study were collected through the Healthy Neighbourhoods project, a cross-sectional survey examining the health and wellbeing of students in 30 communities across three Australian states. School surveys were conducted at two different year levels, primary school grade 6 and secondary school year 8. The communities comprised Australian Bureau of Statistics (ABS) Statistical Local Areas (SLAs), which were randomly selected in the states of Victoria, Queensland and Western Australia after stratification by SES and rurality. Communities were selected equally from regional and urban areas and spread across the full socio-economic range. Quartiles of the index of relative socioeconomic disadvantage from the ABS Socio Economic Indices for Areas (SEIFA) were used to classify community SES. The final sample included eight communities in each of Queensland and Western Australia, and 14 communities in Victoria.

Within each community, a random sample of schools at the grade 6 level and all schools at the grade 8 level were invited to participate. School selection was representative of Catholic, independent and government sectors across each state. Overall $86 \%$ ( $n=483$ ) of schools responded to the invitation to participate (where schools had students in both year 6 and 8 and both levels were approached, these schools were counted twice). Of those schools who responded 53\% agreed to participate; $59 \%$ at the grade 6 level $(n=169)$ and $43 \%$ at grade 8 ( $n=85)$. Due to time constraints, eight schools were not surveyed making the number of participating schools 164 and 82 in grade 6 and 8 respectively. There was no difference in school participation rate by sector or state.

All students in grade 6 and/or grade 8 at participating schools were invited to complete the survey. Students were asked to take home parent information packs containing a consent form and required parental consent to participate in the survey. Of the 15,666 consent forms distributed, 9,830 (63\%) were returned and 885 (9\%) refused consent. On the day of survey $7 \%$ of the students were absent, therefore, from those who returned their form, $83.2 \%(n=4393)$ in grade 6 and $79.9 \%(n=3,635)$ in grade 8 completed the survey. Student participation rates were similar across the three states.

Surveys took place in school terms 3 and 4 (June-December) in 2006. Standard data collection protocols were followed in each state, approved by the University of Melbourne's Human Research Ethics Committee (VIC), the Griffith University Human Research Ethics Committee (QLD) and the Curtin University of Technology Human Research Ethics Committee (WA). Approvals were also obtained from the relevant governing school authorities in each state.

The student survey protocol consisted of an online selfreport instrument that was adapted and expanded from the Communities That Care Youth Survey, which has shown good reliability and validity in large samples. ${ }^{14-16}$ The survey instrument included instructions on how to answer the questions and assurances of confidentiality, which were presented before survey administration by trained study staff members. Surveys were administered online in classrooms during a 45-60 minute period. Where access to the online survey was unavailable, students completed paper-based surveys ( $7 \%$ of total surveys completed).

\section{Measures}

School suspension: Students reported how many times in the past 12 months they had been suspended from school on a five-point scale ranging from Never to 10 or more times. This item did not differentiate between internal 
and external suspension. The number of suspensions was almost always rated as occurring once or twice in the past year. Hence, responses were recoded as 'Yes' (students had been suspended one or more times in the past year) or ' $\mathrm{No}^{\prime}$ (students had not been suspended in the past year) to form a dichotomous measure of school suspension.

Antisocial behaviour: Antisocial behaviour was measured by asking how often in the past 12 months students had: gotten back at another student by not letting them join in your group, told lies or started rumours about another student, called another student mean names or teased him/her in a hurtful way, carried a weapon, stolen something worth more than $\$ 10$, attacked someone with the idea of seriously hurting them, sold illegal drugs, stole or tried to steal a motor vehicle such as a car or motorcycle, been drunk or high at school, threatened someone with a weapon, and beaten up someone so badly that s/he required medical treatment (Cronbach's alpha $=0.81$ ). Response options ranged from Never to 10 or more times on a five-point scale. A mean score was calculated using each of these items. Most students engaged in very few antisocial behaviours. A cut-point was set such that students who engaged in four of the behaviours described at least once were scored as 'Yes' (students who engaged in the behaviours one or more times in the past year) and students who engaged in fewer behaviours than this were scored as 'No' (students who engaged in the less than four of the behaviours listed) to form a dichotomous measure. Approximately $20 \%$ of the sample was scored as 'Yes'.

Risk factors: Risk factors included poor family management, interaction with antisocial peers and academic failure. The mean score for each risk factor scale was calculated, with higher scores reflecting more of the construct.

Poor family management was assessed using nine items including, for example, whether parents would know if the student did not come home on time and whether the family has clear rules about alcohol and drug use (Cronbach's alpha $=0.82$ ). Items were scored on a four-point scale ranging from 1 (definitely yes) to 4 (definitely no).

Interaction with antisocial peers was assessed using eight items that asked students, in the past year, how many of their best friends had been suspended from school, carried a weapon, stolen something worth more than $\$ 10$, sold illegal drugs, stolen or tried to steal a motor vehicle such as a car or motorcycle, been arrested, dropped out of school, or attacked someone with the idea of seriously hurting them (Cronbach's alpha=0.79). All items were rated on a five-point scale ranging from none of my friends to four of my friends.

Academic failure was measured using two items; one asking students what their grades/marks were like last year, putting all of their grades together (rated on a five-point scale from very good to very poor) and another item asking students whether their school grades are better than the grades of most students in their classes (rated on a four-point scale from definitely yes to definitely no). Responses to the former item were rescaled so that scores ranged from one to four and both items had a Spearman's rho of 0.51 (Cronbach's alpha $=0.68$ ).

Demographic characteristics: Demographic characteristics were age, gender and area level SES measured using the SEIFA index of relative socioeconomic disadvantage (an area level measure derived from the ABS Census and described above). A student-reported measure of whether the family owned or was paying off their home was also included as a measure of SES.

\section{Analysis}

Data analyses were conducted in Stata/IC for Windows 10.0. ${ }^{17}$ First, the rates of suspension were calculated for each community included in the study. Next, a series of logistic regression analyses were conducted to examine the association between area level SES and suspension after controlling for age, gender, student reports of the family owning/paying off their home, and antisocial behaviour. However, because the intraclass correlation (ICC) for schools was significant (0.05; 95Cl: 0.04-0.07), suggesting that the correlation for suspension was greater within schools than between schools, multilevel mixed-effects logistical regression was used.

The effect of the interaction between area level SES and antisocial behaviour was also examined, as was the interaction between the family owning/paying off their home and antisocial behaviour. These interactions were not statistically significant $(p<0.10)$ and were therefore excluded from subsequent models. Finally, additional multilevel mixed-effects logistic regression analyses were conducted to test whether the association between area level SES and suspension remained after including the established risk factors of poor family management, academic performance and interaction with antisocial peers. Analyses controlled for the clustering of student responses at the school level.

\section{Results}

\section{Rates of school suspension by area level SES}

Figure 1 shows the rates of school suspension by area level SES. The average rate of school suspension reduces as area level SES increases, changing from $8.7 \%$ for the lowest area level SES to $2.9 \%$ for the highest area level SES (see also Table $1)$. In the middle range of area level SES, the average rates of suspension were $6.1 \%$ and $5.9 \%$ respectively. A chi-square test of the association between the rates of school suspension and area level SES was statistically significant, $\chi^{2}(3)=62.62$, $p<0.001$. Figure 1 also demonstrates variation in average 
community rates of school suspension within each quartile of area level SES. The average rate of suspension across the entire sample was $5.9 \%$.

\section{Descriptive statistics for suspension, antisocial behaviour and risk factors by area level SES}

Table 1 presents the rates of suspension and antisocial behaviour and the mean scores on poor family management, academic failure, and interaction with antisocial peers by area level SES. The chi-square test for the association between antisocial behaviour and area level SES was statistically significant, $\chi^{2}(3)=15.45, p<0.01$. The rates of antisocial behaviour were similar for the lowest and middle levels of area level SES. However, rates of antisocial behaviour were lower for the highest area level SES group. In general, the means for poor family management, academic failure, and interaction with antisocial peers were similar across area level SES. Analyses of variance revealed statistically significant differences on area level SES for interaction with antisocial peers, $\mathrm{F}(40)=2.23, p<0.001$ and academic failure, $F(18)=1.66, p<0.05$. Post hoc Scheffé tests on interaction with antisocial peers revealed significant differences between area level SES categories 1 and 4, 2 and 4 and 3 and 4 . Post hoc tests on academic failure were not statistically significant $(p>0.05)$.

\section{Adjusted association between school suspension and area level SES}

Next we conducted a series of multilevel mixed-effects logistic regression analyses to examine the association between school suspension and area level SES after gradually controlling for more variables in each analysis; the school variable was specified as a random effect. Model 1 examined SES, and owning one's home; each subsequent Model always included SES, and a combination of individual and family variables. As SES was a categorical variable, the comparator variable was the lowest SES quartile (SES level 1). Table 2 shows that students in communities with SES levels 2, 3 and 4 (middle to higher relative to lower levels of area level SES) were protected against the likelihood of being suspended from school. The association between suspension and area level SES remained when analyses controlled for antisocial behaviour, gender, and

Table 1: Descriptive statistics in each area level SES for suspension, antisocial behaviour, poor family management, academic failure and interaction with antisocial peers.

\begin{tabular}{|c|c|c|c|c|}
\hline & SES 1 (low) & SES 2 & SES 3 & SES 4 (high) \\
\hline & $\%(\mathrm{SE})$ & $\%(\mathrm{SE})$ & $\%(\mathrm{SE})$ & $\%(\mathrm{SE})$ \\
\hline Suspension & $8.7 \%(0.7)$ & $6.1 \%(0.3)$ & $5.9 \%(0.5)$ & $2.9 \%(0.2)$ \\
\hline \multirow[t]{2}{*}{ Antisocial behaviour } & $24.2 \%(0.009)$ & $24.2 \%(0.010)$ & $23.0(0.010)$ & $19.7 \%(0.009)$ \\
\hline & Mean (SD) & Mean (SD) & Mean (SD) & Mean (SD) \\
\hline Poor family management & $1.48(0.47)$ & $1.49(0.48)$ & $1.51(0.48)$ & $1.47(0.46)$ \\
\hline Academic failure & $1.90(0.60)$ & $1.92(0.61)$ & $1.94(0.61)$ & $1.89(0.58)$ \\
\hline Interaction with antisocial peers & $0.95(0.31)$ & $0.95(0.29)$ & $0.94(0.29)$ & $0.89(0.22)$ \\
\hline
\end{tabular}

Figure 1: Rates of school suspension in each community organised according to area level socioeconomic status (SES).

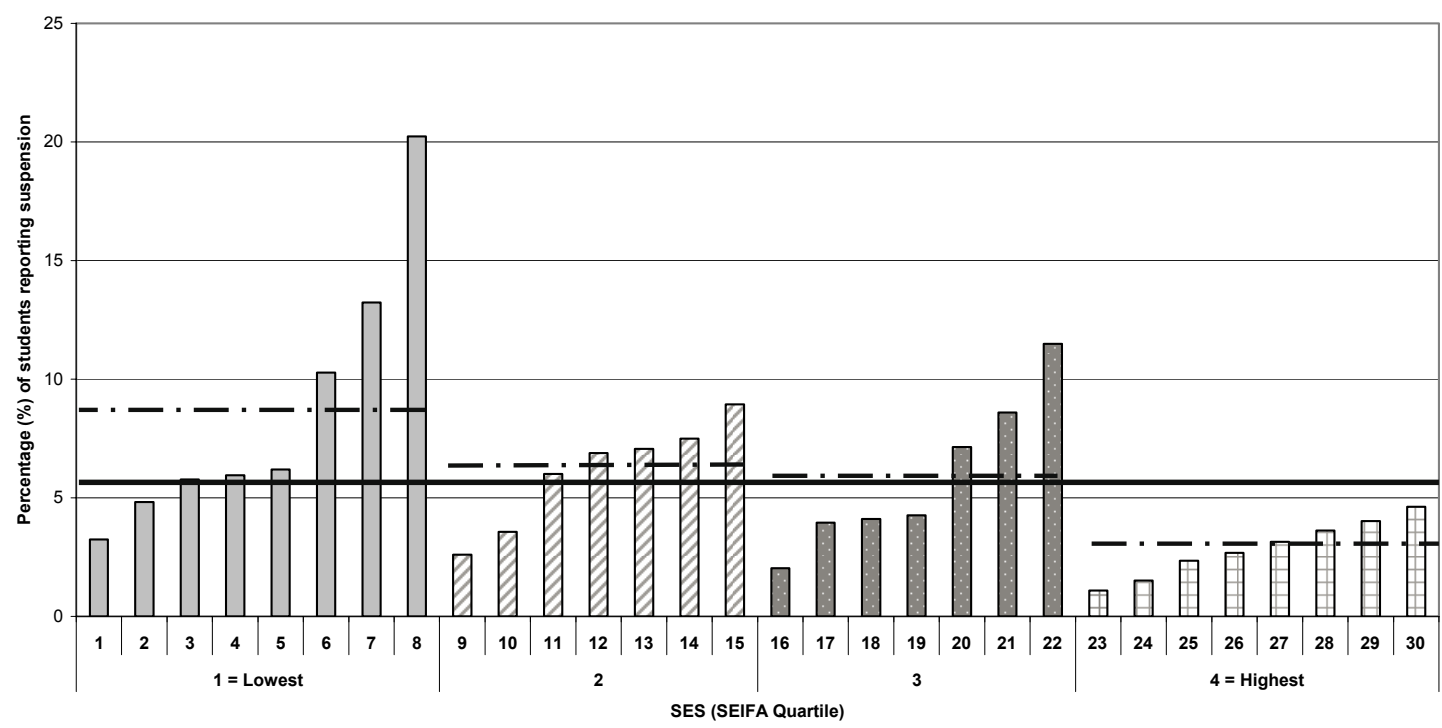

Note: Numbers on the horizontal axis are communities. The black horizontal line on the figure shows the average suspension rate for the entire sample. The black dashed line on the figure shows the average suspension rate in each quartile. 
age, as well as when poor family management, interaction with antisocial peers, and academic failure were included in the analyses. Across the analyses, category 4 of area level SES reduced the likelihood of being suspended by two-thirds, and categories 2 and 3 by one-third. When compared to the null model, models three and five reduced the most variance between the school clusters; model three explained 33\% of the variance $((0.92-0.62) / 0.92)$, and model 5 explained $35 \%$ of the variance $((0.92-.60) / 0.92)$.

\section{Discussion}

Completing an education is an important way for young people from disadvantaged backgrounds to improve their social standing and quality of life. However, existing literature, particularly from the US, reports that students experience a disproportionate exposure to suspension from school when they are from disadvantaged backgrounds including low family income. ${ }^{2,4,9-12}$ The findings of the current study are consistent with previous reports, demonstrating in a large Australian community sample a clear association between student reports of school suspension and area level SES, with lower levels of SES increasing the likelihood of students being suspended. This association remained in analyses that adjusted for gender, age, antisocial behaviour, student reports of the family owning or paying off their home (a proxy for low SES), poor family management, academic failure, and interaction with antisocial peers. Relative to schools in the lowest SES quartile (average 8.7\% annual suspension rate), students in mid-level SES communities had one-third lower suspension rates and in high SES communities the reduction in suspension was two-thirds, after adjustment for other influences.

\section{Implications for schools}

The results of this study have several important implications for schools. First, the study reveals it is feasible to examine links between area level community data and student-reported school suspension. It is crucial that school staff are aware of associations between socio-demographic characteristics including SES and school suspension and that they actively work at being inclusive and use non-exclusionary approaches. Examples of potential preventative alternatives to exclusion are universal implementation of evidence-based violence and bullying prevention and skills training programs (social skills, problem-solving skills, conflict resolutions skills), whole-school restorative practices and peer mediation.

Schools located in low SES communities are often stretched by the number of students whose educational progress is influenced by the burden of adversity and social problems that they bring to school. In such circumstances, schools may resort to counterproductive 'get tough' policies to maintain control. It is critical that schools in disadvantaged areas are provided

\begin{tabular}{|c|c|c|c|c|c|c|c|c|}
\hline & Null Model & Model 1 & Model 2 & Model 3 & Model 4 & Model 5 & Model 6 & Model 7 \\
\hline & & $\begin{array}{l}\text { Adjusted OR } \\
(95 \% \mathrm{Cl})\end{array}$ & $\begin{array}{l}\text { Adjusted OR } \\
(95 \% \mathrm{Cl})\end{array}$ & $\begin{array}{l}\text { Adjusted OR } \\
(95 \% \mathrm{Cl})\end{array}$ & $\begin{array}{c}\text { Adjusted OR } \\
(95 \% \mathrm{CI})\end{array}$ & $\begin{array}{c}\text { Adjusted OR } \\
(95 \% \mathrm{CI})\end{array}$ & $\begin{array}{c}\text { Adjusted OR } \\
(95 \% \mathrm{CI})\end{array}$ & $\begin{array}{c}\text { Adjusted OR } \\
(95 \% \mathrm{CI})\end{array}$ \\
\hline SES - level 2 & & $0.6(0.4-0.9)^{\mathrm{a}}$ & $0.6(0.4-0.9)^{\mathrm{a}}$ & $0.6(0.4-0.9)^{\mathrm{a}}$ & $0.6(0.4-0.9)^{\mathrm{a}}$ & $0.6(0.4-0.9)^{\mathrm{a}}$ & $0.6(0.4-0.9)^{\mathrm{a}}$ & $0.6(0.4-0.9)^{\mathrm{a}}$ \\
\hline SES - level 3 & & $0.6(0.4-0.9)^{\mathrm{a}}$ & $0.6(0.4-0.9)^{\mathrm{a}}$ & $0.6(0.4-0.97)^{\mathrm{a}}$ & $0.6(0.4-0.99)^{a}$ & $0.6(0.4-0.98)^{\mathrm{a}}$ & $0.6(0.4-0.9)^{b}$ & $0.6(0.4-0.97)^{\mathrm{a}}$ \\
\hline SES - level 4 & & $0.3(0.2-0.5)^{\mathrm{c}}$ & $0.3(0.2-0.5)^{c}$ & $0.3(0.2-0.5)^{\mathrm{c}}$ & $0.3(0.2-0.5)^{c}$ & $0.3(0.2-0.5)^{\mathrm{c}}$ & $0.3(0.2-0.5)^{c}$ & $0.3(0.2-0.5)^{c}$ \\
\hline Owns home & & $0.6(0.4-0.7)^{\mathrm{c}}$ & $0.6(0.4-0.7)^{c}$ & $0.5(0.4-0.6)^{c}$ & $0.5(0.4-0.6)^{c}$ & $0.5(0.4-0.7)^{\mathrm{c}}$ & $0.6(0.4-0.7)^{c}$ & $0.6(0.4-0.7)^{\mathrm{c}}$ \\
\hline$A B(0=$ no $A B)$ & & & $6.4(5.2-7.9)^{c}$ & $5.4(4.4-6.7)^{\mathrm{c}}$ & $5.1(4.1-6.4)^{\mathrm{c}}$ & $3.3(2.6-4.2)^{c}$ & $4.8(3.8-6.0)^{c}$ & $3.1(2.4-4.0)^{\mathrm{c}}$ \\
\hline $\begin{array}{l}\text { Gender } \\
(1=\text { male, } 2=\text { fer }\end{array}$ & ale) & & & $0.3(0.2-0.4)^{c}$ & $0.3(0.2-0.4)^{c}$ & $0.3(0.3-0.4)^{c}$ & $0.3(0.2-0.4)^{c}$ & $0.4(0.3-0.5)^{c}$ \\
\hline Age & & & & $1.3(1.1-1.5)^{b}$ & $1.2(1.1-1.5)^{\mathrm{a}}$ & $1.1(1.0-1.4)$ & $1.2(1.0-1.1)^{\mathrm{a}}$ & $1.1(0.9-1.3)$ \\
\hline $\begin{array}{l}\text { Poor family } \\
\text { management }\end{array}$ & & & & & $1.5(1.2-1.8)^{c}$ & & & $1.0(0.8-1.3)$ \\
\hline $\begin{array}{l}\text { Interaction with } \\
\text { antisocial peers }\end{array}$ & & & & & & $5.4(4.1-7.2)^{c}$ & & $5.0(3.8-6.8)^{c}$ \\
\hline $\begin{array}{l}\text { Academic } \\
\text { failure }\end{array}$ & & & & & & & $2.6(2.2-3.1)^{c}$ & $2.5(2.0-3.0)^{c}$ \\
\hline N1 (ind.) & 8029 & 7824 & 7824 & 7802 & 7540 & 7786 & 7726 & 7475 \\
\hline N2 (schools) & 231 & 231 & 231 & 231 & 231 & 231 & 231 & 231 \\
\hline$\sigma 2$ between & .92 & .65 & .62 & .62 & .65 & .60 & .72 & .70 \\
\hline $\mathrm{df}$ & 2 & 6 & 7 & 9 & 10 & 10 & 10 & 12 \\
\hline$-2 \mathrm{LL}$ & -1713.17 & -1620.45 & -1465.36 & -1388.25 & -1332.73 & 1305.05 & -1314.42 & -1206.90 \\
\hline $\mathrm{AIC}$ & 3430.35 & 3252.91 & 2944.72 & 2794.51 & 2685.46 & 2630.09 & 2648.85 & 2437.80 \\
\hline $\mathrm{BIC}$ & 3444.33 & 3294.70 & 2993.48 & 2857.16 & 2754.76 & 2699.70 & 2718.37 & 2520.82 \\
\hline
\end{tabular}

Note: $A B=$ antisocial behaviour; Owns home $=$ student report that family owns or is paying off their home. ind. $=$ individual; $\sigma 2=$ population variance; $d f=d e g r e e s ~ o f ~ f r e e d o m ;-2 L L=$ Likelihood ratio; $A I C=$ Akaike's information criterion; $B I C=$ Bayesian information criterion

a) $p<0.05$; b) $p<0.01$; c) $p<0.001$ 
with a wide range of supports including adequate resourcing and training for teachers to provide quality educational experiences. These schools also need help to find ways of working with other community agencies to manage the complex social problems experienced by their students. ${ }^{18}$

Importantly, there was considerable community variation in rates of student suspension within levels of disadvantage. Schools in low SES areas do not necessarily have high school suspension rates. Raffaele Mendez and colleagues also found that schools with a high proportion of poor minority children did not necessarily have high suspension rates and called for more research on how these schools keep suspension rates down. ${ }^{11}$

\section{Implications for government policy}

Increasingly, guidelines for schools emphasise inclusiveness (e.g. the Victorian Department of Education and Early Childhood Development's Student Engagement Policy Guidelines). ${ }^{19}$ Such guidelines vary across states and jurisdictions, as do rates of suspension. For example, Queensland is reported to have a high rate of school exclusion compared to other states. ${ }^{20}$ To assist schools to shift towards inclusiveness, the use of exclusionary discipline approaches needs to be reduced and policies need to be supported by the provision of resources and school staff skilled in techniques to promote inclusion. In doing so, government policies and programs are more likely to promote health equity by increasing educational and employment opportunities for low SES students. Unemployment is an established risk factor for poorer physical and mental health and mortality. ${ }^{21}$

\section{Strengths and limitations of the study}

The current study includes a large sample of young people aged 10 to 14 years drawn from communities with different levels of socio-economic disadvantage in three states of Australia. Data on disadvantage were drawn from the SEIFA, which is likely to be a more accurate area level measure than reports from students. The sample is not representative of the population, as it was selected to equally represent the quartiles of SES and rurality. As such, these results may not be generalisable to the population. Another limitation of this study is that it is cross-sectional. The long-term impact of area level SES on school suspension cannot be examined here. Further, the measure of school suspension did not specify whether the suspension was external (not allowed to attend school) or internal (student remains in school but is placed in an alternate location outside the usual classroom). It is not clear in this paper that all of the students reported external suspension. Although student reports of school suspension may be considered a limitation, the use of self-report measures provides an important data supplement that can fill gaps in official data and provide a standard means for comparison across states. Self-report studies of pre-adolescents and adolescents are widely accepted as the most reliable source of data for antisocial and violent behaviour. ${ }^{22-24}$

\section{Conclusions}

This study further highlights the link between socio-economic disadvantage and school suspension. Given the unintended negative consequences of school suspension (e.g. exacerbating academic difficulties, crime and delinquency), and that students from disadvantaged backgrounds are often already at risk for these consequences, it is crucial that schools reduce the use of exclusionary approaches. This is particularly so in communities experiencing socio-economic disadvantage. It is important for school staff to first seek to understand why the student is engaging in challenging behaviour and assist students and families to address problems such as learning difficulties, family conflict and family breakdown. Schools can also implement strategies for preventing challenging student behaviour (e.g. violence and bullying prevention and skills training programs). At the policy level, there is a need for continued development of guidelines encouraging schools to be inclusive, as well as providing staff and resources to support the use of non-exclusionary strategies in schools, particularly in disadvantaged communities. Such policies fit with the broader role of schools in promoting the health and wellbeing of their students and will impact on the key social determinants of health including education, social exclusion and income and its distribution.

\section{Acknowledgements}

The authors are grateful for the financial support of the National Health and Medical Research Council (334304) for the Healthy Neighbourhoods Project. Professor Toumbourou is supported by a Victorian Health Promotion Foundation Fellowship. The authors wish to express their appreciation and thanks to project staff and participants for their valuable contribution to the project.

\section{References}

1. American Academy of Pediatrics Committee on School Health. Out-of-school suspension and expulsion. Pediatrics. 2003;112:1206-9.

2. Skiba RJ, Rausch MK. Zero tolerance, suspension, and expulsion: Questions of equity and effectiveness. In: Evertson CM, Weinstein CS, editors. Handbook of Classroom Management: Research, Practice, and Contemporary Issues. Mahwah (NJ): Lawrence Erlbaum Associates; 2006. p. 1063-89.

3. Hemphill SA, Toumbourou JW, Herrenkohl TI, McMorris BJ, Catalano RF. The effect of school suspensions and arrests on subsequent adolescent antisocial behavior in Australia and the United States. J Adolesc Health. 2006;39:736-44.

4. Wu SC, Pink WT, Crain RL, Moles O. Student suspension: A critical reappraisal. The Urban Review. 1982;14(4):245-303.

5. Arcia E. Achievement and enrollment status of suspended students: Outcomes in a large, multicultural school district. Education and Urban Society. 2006;38:359-69. 
6. Butler H, Bond L, Drew S, Krelle A, Seal I. Doing It Differently: improving Young People's Engagement with School. Melbourne (AUST): Brotherhood of St Laurence; 2005.

7. Costenbader V, Markson S. School suspension: A study with secondary school students. J Sch Psychol. 1998;36:59-82.

8. Hemphill SA, Smith R, Toumbourou JW, Herrenkohl TI, Catalano RF, McMorris BJ, et al. Modifiable determinants of youth violence in Australia and the United States: A longitudinal study. Australian and New Zealand Journal of Criminology. 2009;42:289-309.

9. Skiba RJ, Rausch MK. School disciplinary systems: Alternatives to suspension and expulsion. In: Bear GG, Minke KM, editors. Children's Needs III: Development, Prevention, and Intervention. Bethesda (MD): National Association of School Psychologists; 2006. p. 87-102.

10. Skiba RJ, Peterson RL, Williams T. Office referrals and suspensions: Disciplinary intervention in middle schools. Education and Treatment of Children. 1997;20:295-315.

11. Raffaele Mendez LM, Knoff HM, Ferron JM. School demographic variables and out-of-school suspension rates: A quantitative and qualitative analysis of a large, ethnically diverse school district. Psychology in Schools. 2002;39(3):259-77.

12. Christle C, Nelson CM, Jolivette K. School characteristics related to the use of suspension. Education and Treatment of Children. 2004;27(4):509-26.

13. Brantlinger E. Social class distinctions in adolescents' reports of problems and punishment in school. Behavioral Disorders. 1991;17:36-46.

14. Arthur MW, Hawkins JD, Pollard JA, Catalano RF, Baglioni AJ. Measuring risk and protective factors for substance use, delinquency, and other adolescent problem behaviors: The Communities that Care Youth Survey. Evaluation Review. 2002;26:575-601
15. Glaser RR, Van Horn ML, Arthur MW, Hawkins JD, Catalano RF. Measurement properties of the Communities That Care Youth Survey across demographic groups. Journal of Quantitative Criminology. 2005;21:73-102.

16. Pollard JA, Hawkins JD, Arthur MW. Risk and protection: Are both necessary to understand diverse behavioral outcomes? Social Work Research. 1999;23:14558.

17. STATA/IC: data analysis and statistical software. Version 10.0 for Windows. College Station (TX): Stata Corporation; 2007.

18. Riordan G. Reducing student 'suspension rates' and engaging students in learning: Principal and teacher approaches that work. Improving Schools. 2006;9:239-50.

19. Department of Education and Early Childhood Development. Effective Schools are Engaging Schools: Student Engagement Policy Guidelines. Melbourne (AUST): State Government of Victoria; 2009.

20. Bouhours T. The Journey of the Excluded: Schooling and Crime in the Exclusive Society. Brisbane (AUST): Griffith University; 2006.

21. Webster I. Health costs of unemployment. Mental Health in Australia. 1984;1(12):17-23.

22. Huizinga D, Elliott DS. Reassessing the reliability and validity of self-report delinquency measures. Journal of Quantitative Criminology. 1986;2:293327.

23. Jolliffe D, Farrington DP, Hawkins JD, Catalano RF, Hill KG, Kosterman R. Predictive, concurrent, prospective and retrospective validity of self-reported delinquency. Crim Behav Ment Health. 2003;13:179-97.

24. Rutter M, Giller H. Juvenile Delinquency: Trends and Perspectives. Harmondsworth (UK): Penguin; 1983.

\section{Authors}

Sheryl A. Hemphill, Centre for Adolescent Health, Royal Children's Hospital, Department of Paediatrics at The University of Melbourne, Murdoch Childrens Research Institute, \& School of Psychology, Deakin University, Victoria

John W. Toumbourou, School of Psychology, Deakin University, Victoria

Rachel Smith, Centre for Adolescent Health, Royal Children's Hospital, Murdoch Childrens Research Institute, \& the

Department of Paediatrics, The University of Melbourne, Victoria

Garth E. Kendall, Curtin University of Technology \& Telethon Institute for Child Health Research, Perth

Bosco Rowland, Australian Drug Foundation \& School of Psychology, Deakin University, Victoria

Kate Freiberg, Griffith University, Queensland

Joanne W. Williams, Centre for Adolescent Health, Royal Children's Hospital, \& Murdoch Childrens Research Institute, Victoria

\section{Correspondence}

Sheryl Hemphill, Centre for Adolescent Health, 2 Gatehouse Street, Parkville VIC 3052. Fax: (03) 9345 6273;

e-mail: sheryl.hemphill@mcri.edu.au 
Copyright of Health Promotion Journal of Australia is the property of Copyright Agency Limited and its content may not be copied or emailed to multiple sites or posted to a listserv without the copyright holder's express written permission. However, users may print, download, or email articles for individual use. 